\title{
Study of the refractive index of gasoline+alcohol pseudo-binary mixtures
}

\author{
Irina NITA ${ }^{1}$, Elis GEACAI ${ }^{2}$, Olga IULIAN ${ }^{2}$, Sibel OSMAN ${ }^{*}$ \\ ${ }^{I}$ Department of Chemistry and Chemical Engineering, Ovidius University of Constanta, bd. Mamaia 124, \\ 900521, Constanta, Romania \\ ${ }^{2}$ Department of Inorganic Chemistry, Physical Chemistry and Electrochemistry, "Politehnica" University of \\ Bucharest, 132, Calea Grivitei, 010737, Bucharest, Romania
}

\begin{abstract}
The properties of gasoline change as a result of blending with a bioalcohol, affecting the behavior of the pseudo-binary system. The aim of this paper is to present experimental data of the refractive index for pseudobinary mixtures of a reformate gasoline with ethanol, isopropanol and n-butanol over the entire composition range and for temperature ranging from $293.15 \mathrm{~K}$ to $313.15 \mathrm{~K}$. The accuracy of different equations to predict the refractive index of the mixtures was tested. The best prediction accuracy (the lower AAD) corresponded to Eykman and Lorentz-Lorenz mixing rules. A logarithmic equation proposed to correlate the refractive index with composition and temperature of gasoline+alcohol mixtures showed a good accuracy (the absolute average deviation $\mathrm{AAD}<0.052 \%$ ). The deviations in refractive index for investigated systems are negative over the entire composition range and at all investigated temperatures.
\end{abstract}

Keywords: gasoline, alcohol, refractive index, mixing rules, predictive equations.

\section{Introduction}

The environment protection is one of the main challenges of the XXI century. The combustion of the fuels in the vehicle engines is one of the important sources of environment pollution. A way to reduce the impact of transport sector on the environment and to preserve the existing reserves of fossil fuels is the use of biofuels that are made from renewable materials. Biofuels can be used as substitutes or additives for fossil fuels. Bioethanol is currently used as blending component for gasoline in order to reduce pollution from vehicle exhaust gases [1,2]. Other bioalcohols like biopropanol and biobutanol have been received attention due to their advantages over bioethanol: better solubility, less evaporative emissions, combustion efficiency, less flammability and volatility effects, low heating value and reduced corrosion effects [3, 4]. Gasoline is a multicomponent system, composed mainly by different hydrocarbon groups: paraffins, naphtenes, olefins and aromatics.

The proportion of different types of hydrocarbons from a gasoline depends on the characteristics of the raw material, but also on the process by which it was obtained (atmospheric distillation, catalytic cracking, catalytic reforming, isomerization or alkylation). Obviously, the properties of gasoline change as a result of blending with a bioalcohol, affecting the behavior of the pseudo-binary system.

There are many studies presented in literature regarding the properties of gasoline+ethanol system
[5-7], but there is a lack of research on gasoline+propanol or butanol blends [5, 8].

The study of the properties of gasoline blended with bioalcohols is necessary in order to understand the complex behavior of these mixtures. In a previous paper [9] we investigated the refractive index of gasoline $+n$-butanol mixtures at $293.15 \mathrm{~K}$ constant temperature, and density and viscosity at 293.15, $298.15,303.15,308.15,313.15,318.15$ and $323.15 \mathrm{~K}$, respectively.

Refractive index of a liquid mixture can be correlated with other important properties that are more difficult to be measured [10]. Refractive index of gasoline components, as hydrocarbons from paraffins, naphtenes, olefins and aromatics groups, together with other hydrocarbons properties, can be used to predict the octane number of the gasoline. Also, it can be used to develop blending recipes for commercial gasoline that meet quality standards requirements [11] and to assess the quality of this petroleum product [12]. The experimental determination of refractive index can be easily and rapidly done with a proper accuracy using small amounts of sample.

The aim of this paper is to present experimental data of the refractive index of pseudo-binary mixtures consisting in a reformate gasoline with ethanol, isopropanol and $n$-butanol over the entire composition range and for temperature ranging from $293.15 \mathrm{~K}$ to $313.15 \mathrm{~K}$.

\footnotetext{
* Corresponding author. E-mail address: sibel_o@yahoo.ro
} 
The accuracy of different equations to predict the refractive index of the mixtures was assessed. The deviation in refractive index has been calculated and the results have been fitted to Redlich-Kister polynomial equation. Literature survey showed that these refractive index data are new, except our study regarding the refractive index of gasoline $+n$-butanol mixtures at $293.15 \mathrm{~K}$ [9].

\section{Materials and methods}

In this study a reformate gasoline with research octane number (RON) 95 and ethanol, isopropanol and n-butanol of $99.5 \%, 99.0 \%$, and $99.5 \%$ purity, respectively were used. Some properties of gasoline and alcohols used in this study and their corresponding literature values are presented in Table 1. The pseudo-binary gasoline+alcohol mixtures were prepared at room temperature for various volume fractions, in order to cover the entire composition range.

Table 1. Properties of gasoline, ethanol, isopropanol and $n$-butanol

\begin{tabular}{|c|c|c|c|c|c|c|c|}
\hline \multirow{2}{*}{ Property } & Gasoline & \multicolumn{2}{|c|}{ Ethanol } & \multicolumn{2}{|c|}{ Isopropanol } & \multicolumn{2}{c|}{$n$-Butanol } \\
\cline { 2 - 8 } & $\exp$ & $\exp$ & literature & $\exp$ & literature & exp & literature \\
\hline Density at $20^{\circ} \mathrm{C}\left(\mathrm{g} / \mathrm{cm}^{3}\right)$ & 0.7919 & 0.8034 & $0.7909^{[13]}$ & 0.7851 & $0.7855^{[15]}$ & 0.8102 & $0.8101^{[17]}$ \\
& & & $0.7950^{[14]}$ & & $0.7853^{[16]}$ & & $0.8097^{[13]}$ \\
\hline $\begin{array}{c}\text { Dynamic viscosity at } 40^{\circ} \mathrm{C} \\
(\mathrm{mPa} \cdot \mathrm{s})\end{array}$ & 0.3673 & 0.9081 & $0.829^{[18]}$ & 1.3236 & $1.3470^{[16]}$ & 1.7769 & $1.7696^{[21]}$ \\
\hline Refractive index at $20^{\circ} \mathrm{C}$ & 1.4520 & 1.3624 & $1.362^{[22]}$ & 1.3766 & $1.3750^{[23]}$ & 1.3991 & $1.3950^{[22]}$ \\
& & & & & $1.3752^{[24]}$ & & $1.3991^{[25]}$ \\
\hline
\end{tabular}

The experimental uncertainty in volume fraction was estimated to be less than \pm 0.002 . The mixtures were prepared in airtight narrow-mouth ground glass stoppered bottle, in order to minimize the evaporative losses. Refractive index $\left(n_{\mathrm{D}}\right)$ was measured with an Atago 3T refractometer coupled to a thermostated bath, on the wavelength of the sodium D line (589.3 $\mathrm{nm})$ and at atmospheric pressure. The measurements were carried out in the temperature range from 293.15 $\mathrm{K}$ to $313.15 \mathrm{~K}$ at 10 degrees intervals. The uncertainty of refractive index data was of $10^{-4}$ and the accuracy of the temperature of the thermostated bath was of $\pm 0.05 \mathrm{~K}$. The refractometer was calibrated using doubly distilled water at atmospheric pressure according to the instrument operating instructions. All the measurements for each binary mixture at working temperature were repeated three times, and the minimum value of the three measurements was selected in order to eliminate bias caused from evaporation [12].

The accuracy of different mixing rules in the prediction of the refractive index of pseudo-binary gasoline+alcohol mixtures was assessed using the following equations:

- Lorentz-Lorenz equation:

$$
\frac{n_{D}{ }^{2}-1}{n_{D}{ }^{2}+2}=\phi_{1}\left(\frac{n_{D 1}{ }^{2}-1}{n_{D 1}{ }^{2}+2}\right)+\phi_{2}\left(\frac{n_{D 2}{ }^{2}-1}{n_{D 2}{ }^{2}+2}\right)
$$

where $n_{D}$ is the refractive index of the mixture, $n_{D I}$ and $n_{D 2}$ are the refractive indices of the mixture components, $\phi_{1}$ and $\phi_{2}$ are the volume fractions of component 1 and 2, respectively;

- Gladstone-Dale equation:

$$
n_{D}-1=\phi_{1}\left(n_{D 1}-1\right)+\phi_{2}\left(n_{D 2}-1\right)
$$

- Newton equation:

$$
n_{D}^{2}-1=\phi_{1}\left(n_{D 1}^{2}-1\right)+\phi_{2}\left(n_{D 2}^{2}-1\right)
$$

- Eykman equation:

$$
\frac{n_{D}^{2}-1}{n_{D}^{2}+0.4}=\phi_{1}\left(\frac{n_{D 1}^{2}-1}{n_{D 1}^{2}+0.4}\right)+\phi_{2}\left(\frac{n_{D 2}^{2}-1}{n_{D 2}^{2}+0.4}\right)
$$

A Krisnangkura type equation [26] was tested to represents the dependence of refractive index on both mixture composition and temperature:

$$
\ln n_{D}=a+b \phi_{1}+\frac{c}{T}+\frac{d \phi_{1}}{T}
$$

where $a, b, c$ and $d$ are fitting parameters and $\mathrm{T}$ is absolute temperature.

The accuracy of tested equations was evaluated using the absolute average deviation (AAD, \%):

$$
A A D=\frac{100}{n} \sum_{i=1}^{N}\left|\frac{n_{D, \exp , i}-n_{D, c a l, i}}{n_{D, \exp , i}}\right|
$$

where the subscripts exp and cal at refractive index refers to the experimental and calculated values, respectively, and $N$ is the number of experimental data points.

Deviation in refractive index $\Delta n_{D}$ was obtained from experimental refractive index data for the mixture and pure components $(1,2)$ :

$$
\Delta n_{D}=n_{D, \exp }-\left(\phi_{1} n_{D 1}+\phi_{2} n_{D 2}\right)
$$

The deviation in refractive index $\Delta n_{D}$, was correlated with Redlich-Kister equation: 


$$
\Delta n_{D}=\phi_{1} \phi_{2} \sum_{k=0}^{N} A_{k}\left(2 \phi_{1}-1\right)^{k}
$$

where $A_{k}$ are fitting parameters.

The values of $A_{k}$ parameters were determined to minimize the standard deviation $(\sigma)$ of the fit, defined by the equation:

$$
\sigma=\left[\frac{\sum_{i}\left(\Delta n_{D, \text { cali }}-\Delta n_{D, \exp i}\right)^{2}}{n-p}\right]^{1 / 2}
$$

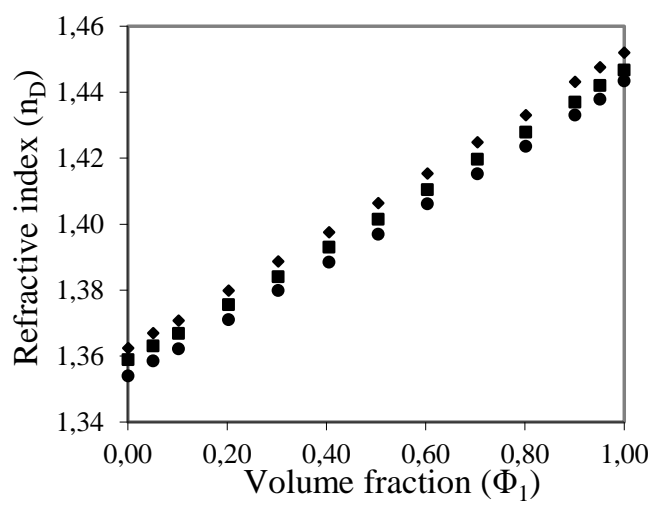

a) where $n$ is the number of experimental data points and $p$ is the number of fitted parameters. The optimum number of fitting parameters from Eq. (9) was determined from examination of the AAD value.

\section{Results and discussion}

Experimental results of refractive index variation with composition and temperature for gasoline+ethanol, gasoline+isopropanol and gasoline $+n$-butanol mixtures are represented in Fig. 1 .

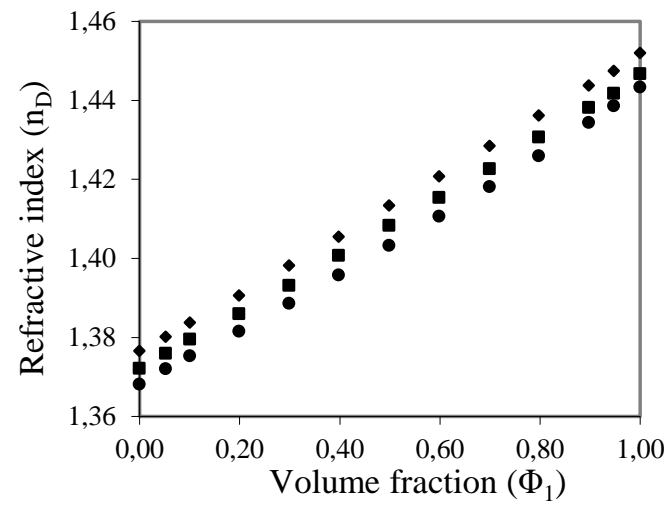

b)

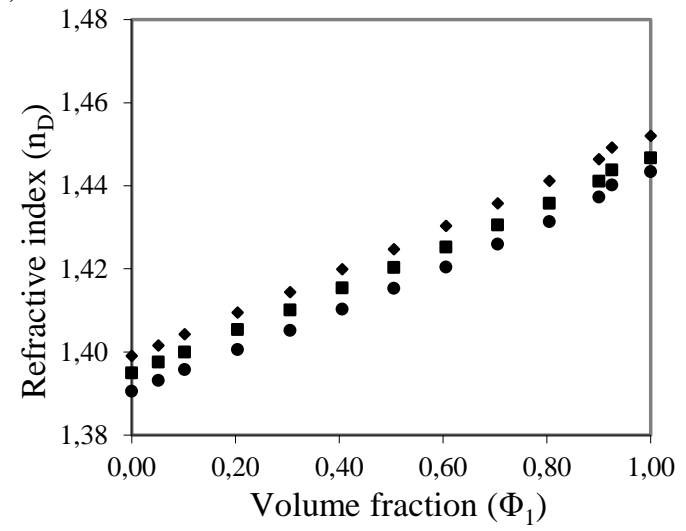

c)

Figure 1. Refractive index versus composition at different temperatures $(\bullet=293.15 \mathrm{~K} ; \boldsymbol{\square}=303.15 \mathrm{~K} ; \bullet=313.15$ K) for: a) gasoline(1)+ethanol(2); b) gasoline(1)+isopropanol(2); c) gasoline(1)+n-butanol(2).

It can be observed that for all gasoline+alcohol mixtures the refractive index increases linearly with gasoline volume fraction at all temperatures. The refractive index decreases with temperature increasing for all investigated systems. It is worth to mention that a comparison of the refractive index measurements was not done in literature due to lack of published data for these investigated systems.

Linear variation of refractive indices with composition for these mixtures and the significant differences between the values of pure components recommends these kind of measurements to determine the composition of gasoline mixtures with alcohol. Based on experimental data, the accuracy of different mixing rules for refractive index prediction from the refractive index of gasoline and pure alcohols, was assessed. Table 2 summarizes the absolute average deviation (AAD \%) of the refractive index calculation using Eqs (1-4). It can be observed that the best prediction accuracy (the lower AAD) corresponded to both Eykman and Lorentz-Lorenz equations for all investigated gasoline+alcohol mixtures.

The refractive index of the gasoline+alcohol mixtures was correlated with composition and temperature using Eq. (5). The values of the empirical parameters, together with the corresponding AADs are presented in Table 3 . The relatively low values of AADs (smaller than $0.052 \%$ ) between the experimental and the calculated data for gasoline+ethanol, gasoline+isopropanol and gasoline $+n$-butanol mixtures, respectively, suggest that the proposed equation satisfactorily correlates the refractive index with temperature and composition. 
Solutions of different alcohols: ethanol, isopropanol and n-butanol mixed with gasoline are not ideal systems as a result of the differences between polar molecules of the alcohol and the nonpolar or slightly hydrocarbon molecules from gasoline, thus resulting in different intermolecular forces and different molecular packing in the mixture, comparing to the pure components. The obtained deviations in refractive index for the gasoline-alcohol

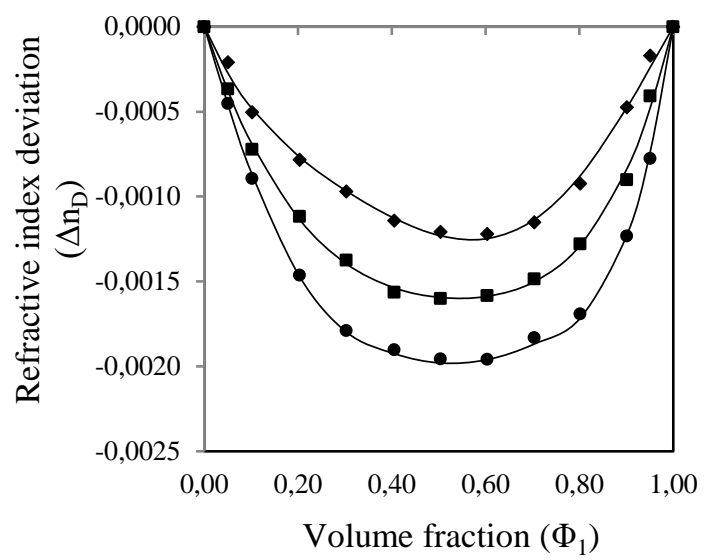

a)

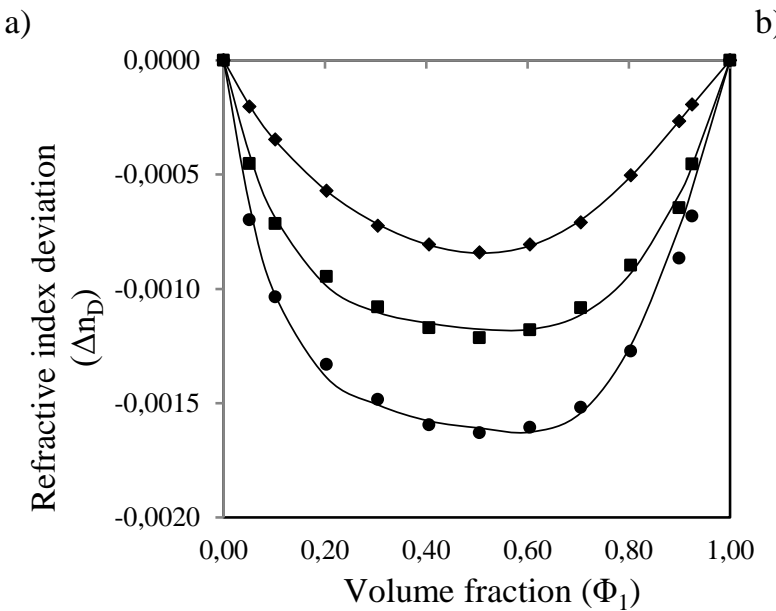

c)

Figure 2. Deviation in refractive index versus volume fraction of gasoline $\left(\Phi_{1}\right)$ at different temperatures ( $=293.15 \mathrm{~K} ; \boldsymbol{\square}=303.15 \mathrm{~K} ; \bullet=313.15 \mathrm{~K}$ ) for: a) gasoline+ethanol; b) gasoline+isopropanol; c) gasoline $+n$ butanol; the points- experimental data, the curves- Redlich-Kister correlation.

Table 2. Absolute average deviation (AAD, \%) for the predictive estimation of refractive index of pseudo-binary gasoline+alcohol mixtures using different equations

\begin{tabular}{|c|c|c|c|}
\hline \multirow{2}{*}{ Equation } & \multicolumn{3}{|c|}{ AAD (\%) } \\
\cline { 2 - 4 } & $\mathbf{2 9 3 . 1 5} \mathbf{~ K}$ & $\mathbf{3 0 3 . 1 5} \mathbf{~ K}$ & $\mathbf{3 1 3 . 1 5}$ K \\
\cline { 2 - 4 } & \multicolumn{3}{|c|}{ Gasoline+ethanol } \\
\hline Lorentz-Lorenz & 0.021 & 0.043 & 0.060 \\
\hline Gladstone-Dale & 0.042 & 0.069 & 0.085 \\
\hline Newton & 0.068 & 0.096 & 0.113 \\
\hline Eykman & 0.025 & 0.008 & 0.022 \\
\hline Lorentz-Lorenz & \multicolumn{3}{|c|}{ Gasoline+isopropanol } \\
\hline Gladstone-Dale & 0.023 & 0.038 & 0.046 \\
\hline
\end{tabular}




\begin{tabular}{|c|c|c|c|}
\hline Newton & 0.062 & 0.076 & 0.120 \\
\hline Eykman & 0.002 & 0.013 & 0.056 \\
\hline Lorentz-Lorenz & \multicolumn{3}{|c|}{ Gasoline+ $\boldsymbol{n}$-butanol } \\
\hline Gladstone-Dale & 0.021 & 0.024 & 0.063 \\
\hline Newton & 0.031 & 0.033 & 0.072 \\
\hline Eykman & 0.040 & 0.042 & 0.082 \\
\hline
\end{tabular}

Table 3. Fitting parameters and absolute average deviation (AAD, \%) of the correlation of the refractive index with composition and temperature of gasoline+alcohol mixtures using Eq. (5)

\begin{tabular}{|c|c|c|c|c|c|c|}
\hline \multirow[t]{2}{*}{ System } & \multicolumn{4}{|c|}{ Parameter } & \multirow{2}{*}{$\begin{array}{l}\text { Temperature } \\
\text { (K) }\end{array}$} & \multirow{2}{*}{$\begin{array}{c}\text { AAD } \\
(\%)\end{array}$} \\
\hline & $a$ & $b$ & $c$ & $d$ & & \\
\hline \multirow[t]{3}{*}{ Gasoline+ethanol } & \multirow[t]{3}{*}{0.2108} & \multirow[t]{3}{*}{0.0567} & \multirow[t]{3}{*}{28.8530} & \multirow[t]{3}{*}{1.9925} & 293.15 & 0.0209 \\
\hline & & & & & 303.15 & 0.0275 \\
\hline & & & & & 313.15 & 0.0257 \\
\hline \multirow{3}{*}{ Gasoline+isopropanol } & \multirow[t]{3}{*}{0.2181} & \multirow[t]{3}{*}{0.0487} & \multirow[t]{3}{*}{29.7020} & \multirow[t]{3}{*}{1.3130} & 293.15 & 0.0125 \\
\hline & & & & & 303.15 & 0.0299 \\
\hline & & & & & 313.15 & 0.0513 \\
\hline \multirow{3}{*}{ Gasoline $+n$-butanol } & \multirow[t]{3}{*}{0.2471} & \multirow[t]{3}{*}{0.0329} & \multirow[t]{3}{*}{28.9170} & \multirow[t]{3}{*}{1.2178} & 293.15 & 0.0210 \\
\hline & & & & & 303.15 & 0.0320 \\
\hline & & & & & 313.15 & 0.0499 \\
\hline
\end{tabular}

Table 4. Fitting parameters of Redlich-Kister equation and corresponding standard deviations $(\sigma)$ for deviation in refractive index of gasoline+alcohol mixtures

\begin{tabular}{|c|c|c|c|c|c|c|}
\hline \multirow[t]{2}{*}{ System } & \multirow{2}{*}{$\begin{array}{c}\text { Temperature } \\
\text { (K) }\end{array}$} & \multicolumn{4}{|c|}{ Parameter } & \multirow[t]{2}{*}{$\sigma$} \\
\hline & & $A_{0}$ & $A_{l}$ & $A_{2}$ & $A_{3}$ & \\
\hline \multirow[t]{3}{*}{ Gasoline+ethanol } & 293.15 & -0.0049 & -0.0014 & -0.0006 & 0.0022 & 0.0028 \\
\hline & 303.15 & -0.0064 & -0.0005 & -0.0033 & -0.0009 & 0.0014 \\
\hline & 313.15 & -0.0078 & 0.0002 & -0.0060 & -0.0045 & 0.0018 \\
\hline \multirow{3}{*}{ Gasoline+isopropanol } & 293.15 & -0.0046 & 0.0004 & -0.0035 & -0.0026 & 0.0026 \\
\hline & 303.15 & -0.0053 & 0.0002 & -0.0047 & -0.0028 & 0.0027 \\
\hline & 313.15 & -0.0062 & 0.0002 & -0.0069 & -0.0046 & 0.0027 \\
\hline \multirow{3}{*}{ Gasoline $+n$-butanol } & 293.15 & -0.0034 & -0.0002 & $-2.6 \mathrm{E}-05$ & 0.0011 & 0.0001 \\
\hline & 303.15 & -0.0047 & -0.0004 & -0.0036 & 0.0016 & 0.0022 \\
\hline & 313.15 & -0.0064 & -0.0008 & -0.0060 & 0.0031 & 0.0029 \\
\hline
\end{tabular}

From Figure 2 it can be observed that the deviations in refractive index $\left(\Delta n_{D}\right)$ for investigated systems are negative over the entire composition range and at all investigated temperatures. The deviation in refractive index increases with temperature increasing.

\section{Conclusions}

The conclusions arising from this study are the followings:

- the refractive index of gasoline+ethanol, gasoline+isopropanol and gasoline $+n$ butanol mixtures increases with gasoline volume fraction and decreases with temperature increasing;

- the refractive index of the studied gasoline+alcohol mixtures can be accurately predicted from the refractive index of gasoline and alcohol, using both Eykman and Lorentz-Lorenz mixing rules;

- the deviations in refractive index $\left(\Delta n_{D}\right)$ are negative over the entire composition range and at all investigated temperatures;

- the refractive indices can be used to determine the composition of these gasoline+alcohol systems.

\section{Conflict of interests}

The authors declare that there is no conflict of interests.

\section{References}

[1]. A.K. Thakur, A.K. Kaviti, R. Mehra, K.K.S. Mer, Progress in performance analysis of ethanol-gasoline blends on SI engine 
Renewable and Sustainable Energy Reviews 69 (2017) 324-340. https://doi.org/10.1016/j.rser.2016.11.056

[2]. V. Thangavel, S.Y. Momula, D.B. Gosala, R. Asvathanarayanan, Experimental studies on simultaneous injection of ethanol-gasoline and n-butanol-gasoline in the intake port of a four stroke SI engine, Renewable Energy 91 (2016) 347-360. https://doi.org/10.1016/j.renene.2016.01.074

[3]. Y. Li, L. Meng, K. Nithyanandan, T. H. Lee, Y. Lin, C.F. Lee, S. Liao, Combustion, performance and emissions characteristics of a spark-ignition engine fueled with isopropanoln-butanol-ethanol and gasoline blends, Fuel 184 (2016) 864-872. https://doi.org/10.1016/j.fuel.2016.07.063

[4]. E.J. Barrientos, J.E. Anderson, M.M. Maricq, A.L. Boehman, Particulate matter indices using fuel smoke point for vehicle emission with gasoline, ethanol blends, and butanol blends, Combustion and Flame 167 (2016) 308-319. https://doi.org/10.1016/j.combustflame.2016.0 1.034

[5]. B.M. Masum, H.H. Masjuki, M.A. Kalam, S.M. Palash, M. Habibullah, Effect of alcoholgasoline blends optimization on fuel properties, performance and emissions of a SI engine, Journal of Cleaner Production 86 (2015) 230237. https://doi.org/10.1016/j.jclepro.2014.08.032

[6]. T.M. Foong, K.J. Morganti, M.J. Brear, The octane numbers of ethanol blended with gasoline and its surrogates, Fuel 115 (2014) 727-739.

https://doi.org/10.1016/j.fuel.2013.07.105

[7]. L.M. Rodriguez-Anton, M. HernandezCampos, F. Sanz-Perez, Experimental determination of some physical properties of gasoline, ethanol and ETBE blends, Fuel 112 (2013) 178-184. https://doi.org/10.1016/j.fuel.2013.04.087

[8]. L.M. Rodriguez-Anton, F. Gutierrez-Martin, Y. Doce, Physical properties of gasoline, isobutanol and ETBE binary blends in comparison with gasoline ethanol blends, Fuel 166 (2016) 73-78.

http://dx.doi.org/10.1016/j.fuel.2015.10.106

[9]. I. Nita, O. Iulian, E. Geacai, S. Osman, Physicochemical properties of the pseudo-binary mixture gasoline +1 - butanol, Energy Procedia 95 (2016) 330-336. https://doi.org/10.1016/j.egypro.2016.09.017

[10]. I. Nita, S. Geacai, A. Neagu, E. Geacai, Estimation of the refractive index of diesel fuel+biodiesel blends, Ovidius University Annals of Chemistry 24 (2013) 24-26. https://doi.org/10.2478/auoc-2013-0005
[11]. B.V. Sakhnevitch, M.V. Kirgina, N.V. Chekancev, E.D. Ivanchina, A.A. Syskina, Complex System for Gasoline Blending Maintenance, Procedia Chemistry 10 (2014) 289-296. https://doi.org/10.1016/j.proche.2014.10.049

[12]. V.F. Nikolaev, I.I. Tabrisov, A.I. Penkovsky, R.B. Sultanova, Express method for total content assessment of aromatic hydrocarbons and oxygen in finished gasolines by refractometry and densimetry, Fuel 142 (2015) 94-101. http://dx.doi.org/10.1016/j.fuel.2014.10.042

[13]. H. Wei, D. Feng, J. Pan, J. Shao, M. Pan, Knock characteristics of SI engine fueled with nbutanol in combination with different EGR rate, Energy 118 (2017) 190-196. https://doi.org/10.1016/j.energy.2016.11.134

[14]. P.S. Veloo, Y.L. Wang, F.N. Egolfopoulos, C.K. Westbrook, A comparative experimental and computational study of methanol, ethanol, and $n$-butanol flames, Combustion and Flame 157 (2010) 1989-2004. https://doi.org/10.1016/j.combustflame.2010.0 4.001

[15]. X. Wang, A.B. Eberhardt, E. Galluci, K. Scrivener, Assessment of early age properties of cementitious system through isopropanol-water replacement in the mixing water, Cement and Concrete Research 84 (2016) 76-84.

https://doi.org/10.1016/j.cemconres.2016.02.00 9

[16]. F.M. Pang, C.E. Seng, T.T. Teng, M.H. Ibrahim, Densities and viscosities of aqueous solutions of 1-propanol and 2-propanol at temperatures from $293.15 \mathrm{~K}$ to $333.15 \mathrm{~K}$, Journal of Molecular Liquids 136 (2007) 71-78. https://doi.org/10.1016/j.molliq.2007.01.003

[17]. V.V.E. Prasad, S.B. Agrawal, A.B. Bajaj, D.H.L. Prasad, Density and Viscosity of Methanol + Trichloroethylene, $n$-Propanol + Trichloroethylene and n-Butanol + Trichloroethylene Mixtures, Physics and Chemistry of Liquids. An International Journal 38 (2000) 433-438. http://dx.doi.org/10.1080/00319100008030290

[18]. E. Quijada-Maldonado, G.W. Meindersma, A.B. de Haan, Viscosity and density data for the ternary system water(1)-ethanol(2)-ethylene glycol(3) between $298.15 \mathrm{~K}$ and $328.15 \mathrm{~K}$, Journal of Chemical Thermodynamics 57 (2013) 500-505. http://dx.doi.org/10.1016/j.jct.2012.08.024

[19]. W. Qian, Y. Xu, H. Zhu, C. Yu, Properties of pure 1-methylimidazolium acetate ionic liquid and its binary mixtures with alcohols, Journal of Chemical Thermodynamics 49 (2012) 87-94. http://dx.doi.org 10.1016/j.jct.2012.01.013 
[20]. M.J. Lee, T.K. Lin, Density and Viscosity for Monoethanolamine + Water, + Ethanol, and + 2-Propanol, Journal of Chemical Engineering Data 40 (1995) 336-339. DOI: 10.1021/je00017a074

[21]. S. Mrad, M. Hichri, I. Kattech, C. Lafuente, Thermophysical study of the binary mixtures of $\mathrm{N}, \mathrm{N}$-dimethylacetamide with 1-propanol and 1-butanol, Journal of Molecular Liquids 231 (2017) 168-173. https://doi.org/10.1016/j.molliq.2017.02.005

[22]. P.G. Aleiferis, Z.R. van Romunde, An analysis of spray development with iso-octane, npentane, gasoline, ethanol and n-butanol from a multi-hole injector under hot fuel conditions, Fuel 105 (2013) 143-168. http://dx.doi.org/10.1016/j.fuel.2012.07.044

[23]. A.E. Andreatta, M. Francisco, E. Rodil, A. Soto, Isobaric vapour-liquid equilibria and physical properties for isopropyl acetate + isopropanol + 1-butyl-3-methyl-imidazolium bis(trifluoromethylsulfonyl)imide mixtures,
Fluid Phase Equilibria 300 (2011) 162-171. https://doi.org/10.1016/j.fluid.2010.10.003

[24]. J.A. Riddick, W.B. Bunger, T. Sakano, Organic Solvents, $4^{\text {th }}$ ed., John Wiley, New York, 1986.

[25]. L.F. Sanz, J.A. Gonzales, I.G. de La Fuente, J.C. Cobos, Thermodynamics of mixtures with strongly negative deviations from Raoult's law. XI. Densities, viscosities and refractives indices at (293.15-303.15) K for cyclohexylamine + 1propanol, or +1-butanol systems, Journal of Molecular Liquids 172 (2012) 26-33. https://doi.org/10.1016/j.molliq.2012.05.003

[26]. K. Krisnangkura, C. Sansa-ard, K. Aryusuk, S. Lilitchan, K. Kittiratanapiboon, An empirical approach for predicting kinematic viscosities of biodiesel blends, Fuel 89 (2010) 2775-2780. https://doi.org/10.1016/j.fuel.2010.04.033

Received: 9.03.2017

Received in revised form: 13.05.2017

Accepted: 15.05.2017 